CLINICAL STUDY

\title{
Randomized GH trial with two different dosages in combination with a GnRH analogue in short small for gestational age children: effects on metabolic profile and serum GH, IGF1, and IGFBP3 levels
}

\author{
Daniëlle van der Kaay ${ }^{1,2}$, Boudewijn Bakker ${ }^{3}$, Flip van der Hulst ${ }^{4}$, Dick Mul ${ }^{5}$, Jaap Mulder ${ }^{6}$, Eelco Schroor ${ }^{7}$, \\ Denise van Elswijk $^{1,2}$, Inge Rowaan ${ }^{1,2}$, Merel Willeboer ${ }^{1,2}$, Maria de Ridder ${ }^{2,8}$ and Anita Hokken-Koelega ${ }^{1,2}$ \\ ${ }^{1}$ Division of Endocrinology, Department of Pediatrics, Erasmus Medical Center, Rotterdam, The Netherlands, ${ }^{2}$ Dutch Growth Research Foundation, PO Box \\ 23068, 3001 KB Rotterdam, The Netherlands, ${ }^{3}$ Department of Pediatrics, Reinier de Graaf Guesthouse, Delft, The Netherlands, ${ }^{4}$ Department of Pediatrics, \\ Zaans Medical Center, Zaandam, The Netherlands, ${ }^{5}$ Department of Pediatrics, Haga Teaching Hospital and Juliana Children's Hospital, Den Haag, The \\ Netherlands, ${ }^{6}$ Department of Pediatrics, Rijnstate Hospital, Arnhem, The Netherlands, ${ }^{7}$ Department of Pediatrics, Isala Clinics, Zwolle, The Netherlands \\ and ${ }^{8}$ Department of Epidemiology and Biostatistics, Erasmus Medical Center, Rotterdam, The Netherlands \\ (Correspondence should be addressed to D van der Kaay at Dutch Growth Research Foundation; Email: d.vanderkaay@erasmusmc.nl)
}

\begin{abstract}
Background: GnRH analogue (GnRHa) combined with GH treatment has been proposed to increase adult height. Effect on metabolic profile and GH, IGF1, and IGFBP3 levels in short small for gestational age (SGA) children is unknown.

Objective: To assess fat mass and lean body mass SDS, percentage trunk fat, blood pressure (BP), insulin sensitivity ( $\mathrm{Si}$ ), $\beta$-cell function (disposition index, DI), lipid profile, and GH, IGF1, and IGFBP3 levels during 2 years of combined treatment.

Subjects: Forty-one pubertal short SGA children with a mean $( \pm$ s.D. $)$ age of $12.1( \pm 1.0)$ years.

Design: Children received $3.75 \mathrm{mg}$ of leuprolide acetate depot subcutaneously every 4 weeks, and they were randomly assigned to receive $1 \mathrm{mg}$ (group A) or $2 \mathrm{mg}$ (group B) of $\mathrm{GH} / \mathrm{m}^{2}$ per day.

Results: Percentage trunk fat increased in both groups, but to a lower extent in group B. Lean body mass SDS increased only in group B. Changes in BP, Si, DI, and lipids were similar in both groups. Si significantly decreased, but DI remained unchanged. Lipids remained normal. GH and IGF1 levels were significantly higher in group B.

Conclusion: Our study is the first to report that 2 years of combined treatment with a GnRHa and either 1 or $2 \mathrm{mg} \mathrm{GH} / \mathrm{m}^{2}$ per day does not adversely affect body composition and metabolic profile of short SGA children who come under medical attention at the onset of puberty. There was a dose-dependent effect on fat mass SDS height $_{\text {, percentage trunk fat, lean body mass SDS }}$ height, and GH and IGF1 levels in favor of treatment with GnRHa and the higher GH dose of $2 \mathrm{mg} / \mathrm{m}^{2}$ per day.
\end{abstract}

European Journal of Endocrinology 162 887-895

\section{Introduction}

GnRH analogue (GnRHa) treatment has long been used in children with central precocious puberty (CPP). Over the years, little attention has been paid to changes in metabolic profile during GnRHa treatment. Studies have focused on body composition, and were performed in children with CPP only. Some studies reported an increase in fat mass or body mass index (BMI) SDS during GnRHa treatment with a return to baseline values after discontinuation $(1,2)$, whereas others reported no changes (3) or even a decreased BMI SDS during GnRHa treatment (4).

In prepubertal short children born small for gestational age (SGA), GH treatment induces catch-up growth (5-7). Metabolic effects of GH treatment in prepubertal short SGA children include the development of relative insulin resistance (IR) $(8,9)$ with an improvement of blood pressure (BP) and lipid profile (10). Fat mass SDS adjusted for gender and height declined significantly, whereas the increase in lean body mass SDS adjusted for gender and height reflected the normal increase as a result of the increase in height (11). In a randomized clinical trial where prepubertal short SGA children were treated with 1 or $2 \mathrm{mg} \mathrm{GH} / \mathrm{m}^{2}$ per day, no significant differences in BMI SDS, BP, insulin levels, and lipid profile were found between the two GH dosage groups $(8,10)$.

Pubertal short SGA children are frequently treated with GnRHa along with different dosages of $\mathrm{GH}$ to optimize adult height, despite the fact that no data are available about the $\mathrm{GH}$ dose effect of combined 
treatment on metabolic profile and $\mathrm{GH}$, insulin-like growth factor 1 (IGF1), and IGF binding protein 3 (IGFBP3) levels.

In the present randomized trial, we investigated the effect of 2 years of combined treatment with GnRHa and two different dosages of GH (1 vs $2 \mathrm{mg} \mathrm{GH} / \mathrm{m}^{2}$ per day) on body composition, BP, insulin sensitivity $(\mathrm{Si}), \beta$-cell function, and lipid profile in pubertal short SGA children. Furthermore, we measured serum GH, IGF1, and IGFBP3 levels at the start of GH treatment and after 1 year of combined treatment and associated levels with the metabolic profile.

\section{Materials and methods}

\section{Subjects}

The study group consisted of 45 short SGA children (29 girls) who were at the beginning of puberty. They were included in a randomized trial investigating two dosages of GH in combination with GnRHa treatment $(3.75 \mathrm{mg}$ of s.c. leuprolide acetate depot given every 4 weeks). Children who met the following inclusion criteria were included in the study: i) birth length and/or birth weight SDS below -2 for gestational age (12), ii) chronological age of 8 years or older at the start of the study, iii) current height SDS below -2.5 or a predicted adult height SDS below -2.5 (calculated as height at the start of puberty plus $20 \mathrm{~cm}$ for girls and plus $30 \mathrm{~cm}$ for boys, according to Dutch references (13)), and iv) early pubertal stage, defined as Tanner breast stage 2 or 3 in girls and a testicular volume of $4-8 \mathrm{ml}$ in boys (14), and a GnRH agonist test result indicating central puberty (peak LH $10 \mathrm{IU} / \mathrm{l}$ or more) (15). Exclusion criteria were i) a complicated neonatal period, with signs of severe asphyxia (defined as Apgar score $<3$ after $5 \mathrm{~min}$ ), ii) long-term complications of respiratory ventilation such as bronchopulmonary dysplasia, iii) endocrine or metabolic disorders, chromosomal defects, growth failure caused by other disorders (such as emotional deprivation, severe chronic illness, and chondrodysplasia) or syndromes (except for SilverRussell syndrome, no children with Silver-Russell syndrome were included in this study), and iv) previous or present medication that could interfere with growth or GH treatment. The study was approved by the medical ethics committee of the participating centers, and written informed consent was obtained from parents or custodians and children aged 12 years or older.

Four children (two in each $\mathrm{GH}$ dosage group) were excluded during the 2-year observation period. Two girls did not meet the response criteria retrospectively. Treatment was stopped in one girl and one boy because of non-compliance.

\section{Study design}

After 3 months of GnRHa treatment, children were randomized into two GH dosage groups after stratification for gender, pubertal stage (Tanner stage 2 or 3), and parental height SDS (one parent with height SDS below -2 or both parents with height SDS within the normal range; Fig. 1). Children were assigned to group A receiving $1 \mathrm{mg} \mathrm{GH} / \mathrm{m}^{2}$ per day $(\sim 0.033 \mathrm{mg} / \mathrm{kg}$ per day) or to group B receiving $2 \mathrm{mg} \mathrm{GH} / \mathrm{m}^{2}$ per day ( $0.067 \mathrm{mg} / \mathrm{kg}$ per day), Genotropin (Somatropin). GH was administered subcutaneously once daily at bedtime. The GH dose was adjusted to the calculated body surface area thrice monthly.

Complete overnight $\mathrm{GH}$ profiles were determined in 33 children as described previously (16), one at the start of GH treatment and one after $\sim 1$ year of combined treatment following a s.c. GH injection at $2000 \mathrm{~h}$. Height was measured using a Harpenden stadiometer, and was expressed as SDS for calendar age and sex (13). Systolic and diastolic BPs were measured with an automated device. The mean of three measurements was used for analysis. Since height is an important determinant of BP, BP was expressed as SDS to adjust for height and gender (17). Fat mass and lean body mass were measured by dual-energy X-ray absorptiometry scans on one machine (DXA; Lunar Prodigy, GE Healthcare, Chalfont, St Giles, UK). Fat mass and

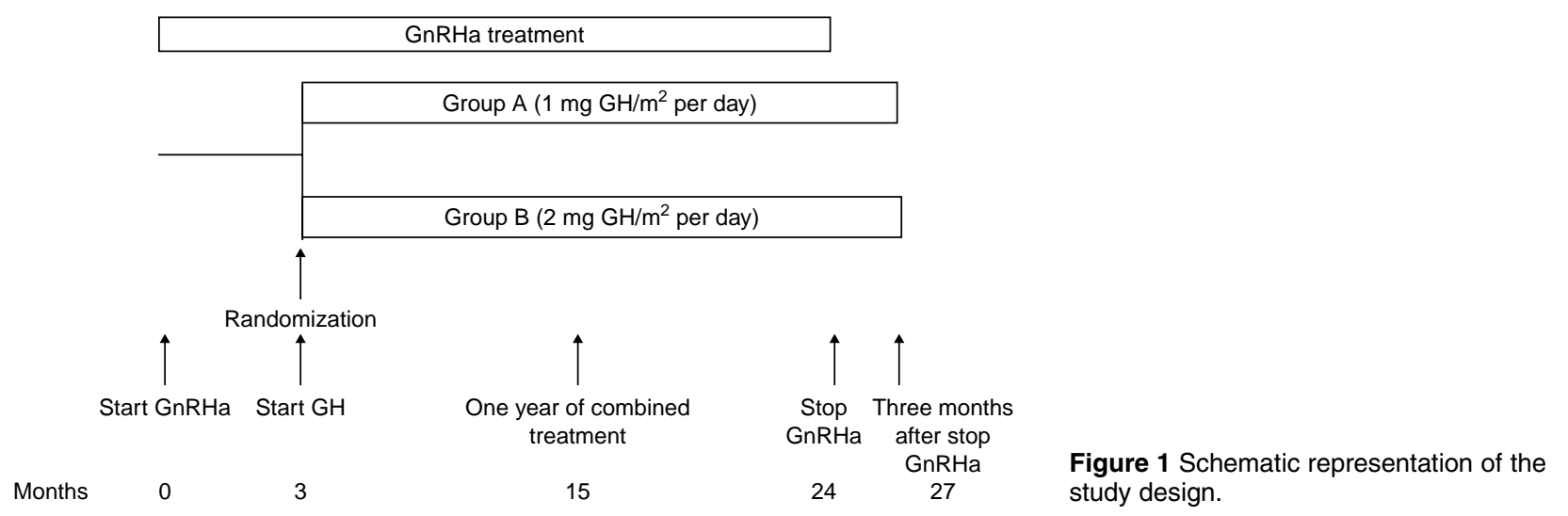

www.eje-online.org 
lean body mass were expressed as SDS to adjust for gender and height (SDS height (18). Percentage trunk fat was calculated as (trunk fat/total trunk mass) $\times 100$.

\section{Glucose homeostasis}

At the start of GnRHa treatment and after 1 year of combined treatment, a modified frequently sampled i.v. glucose tolerance test (FSIGT) with tolbutamide was performed as described previously (19). Si, glucose effectiveness $(\mathrm{Sg})$, acute insulin response (AIR), and disposition index (DI) were calculated using Bergman's MINMOD Millennium software (20). Si quantifies the capacity of insulin to stimulate glucose disposal, and $\mathrm{Sg}$ reflects the capacity of glucose to mediate its own disposal. The AIR, an estimate of insulin secretory capacity, was measured as the area under the curve from 0 to 10 min corrected for baseline insulin levels. DI is calculated as $\mathrm{AIR} \times \mathrm{Si}$, and is an estimate of $\beta$-cell function.

\section{Hormone assays}

Fasting insulin levels during FSIGTs were measured in one laboratory (IRMA; Medgenix, Biosource Europe, Nivelles, Belgium). The intra-assay coefficient of variance (CV) was $1.9 \%$, and the inter-assay $C V$ was $6.3 \%$. Fasting insulin levels at 3 months after the end of GnRHa treatment were measured using a chemiluminescent assay on an Immulite 2000 analyzer (Diagnostic Products Corporation, Los Angeles, CA, USA). Both methods were highly correlated $\left(r^{2}=0.98\right)$ using the following formula: Y (Immulite $)=0.6922 \mathrm{X}$ (IRMA) 0.1761. A conversion factor of 6.89 was used to transform data from mU/l (IRMA) to pmol/l (Immulite). Homeostasis model assessment (HOMA)-IR index was calculated using a computer model (21). Total cholesterol (TC), low density lipoprotein-cholesterol (LDL-c), high density lipoprotein-cholesterol, non-esterified fatty acids (FFAs), and triglycerides (TGs) were determined as described previously (22). Apolipoprotein A1 (Apo-A1), apolipoprotein B (Apo-B), and lipoprotein (a) (lp(a)) were determined by rate nephelometry on the IMMAGE Immunochemistry system according to the manufacturer's instructions (Beckman Coulter, Mijdrecht, The Netherlands). Between-run CV values were 4.2, 2.8, and $6.9 \%$ for the lipoproteins at the levels of $0.94,0.53$, and $0.35 \mathrm{~g} / \mathrm{l}$ respectively. GH, IGF1, and IGFBP3 levels were measured as described previously (16).

\section{Statistical analysis}

Results for body composition, BP, Si, $\beta$-cell function, and lipid profile are presented as mean ( \pm s.D). Percentage trunk fat, AIR, DI, insulin levels, HOMA-IR, and TG and lp(a) levels were log-transformed before analysis in order to have a Gaussian distribution. SDS were compared with population means (zero SDS) using one-sample $t$-tests. To correct for multiple testing and some missing data, the changes over time and differences between groups A and B were analyzed using repeated-measurement analysis with a categorical effect for time and an interaction term for time and GH dose (SAS 9.1 (SAS Institute Inc., Cary, NC, USA)).

GH profiles were analyzed using the Pulsar program (23, 24). Mean and maximum GH levels were derived from this program. Analyses were performed using the statistical package SPSS (version 11.0; SPSS Inc., Chicago, IL, USA) for Windows, and the results for GH profiles and IGF1 and IGFBP3 levels are expressed as median (interquartile range). The Mann-Whitney test was used for differences between groups. The Wilcoxon signed rank test was used to determine differences between points in time within groups. To test for linear relationships, partial correlations were determined for groups A and B together, with adjustment for $\mathrm{GH}$ dosage. A $P$ value $<0.05$ was considered significant.

\section{Results}

\section{Clinical characteristics}

Table 1 lists the clinical data. At the start of GH treatment, all children had clinical suppression of puberty and prepubertal overnight LH and FSH profile patterns as we reported previously $(25,26)$. No significant differences were found between groups A and $\mathrm{B}$ or between boys and girls.

\section{Metabolic profile during combined treatment}

All analyses were adjusted for gender and Tanner stage at the start of GnRHa treatment, since body composition, $\mathrm{Si}$, and several lipid parameters were significantly different between boys and girls or between children with Tanner stages 2 and 3.

Table 1 Clinical characteristics of short small for gestational age (SGA) children. Data are expressed as mean ( \pm s.D.).

\begin{tabular}{lcc}
\hline & $\begin{array}{c}\text { Group A (1 mg } \\
\text { GH/m }\end{array}$ & $\begin{array}{c}\text { Group B }(2 \mathrm{mg} \\
\text { GH/m }\end{array}$ \\
\hline Number (female) & $22(13)$ & $19(13)$ \\
Gestational age (weeks) & $38.3( \pm 2.4)$ & $37.3( \pm 3.5)$ \\
Birth weight SDS & $-2.0( \pm 1.1)$ & $-1.9( \pm 0.83)$ \\
Birth length SDS & $-2.7( \pm 1.1)$ & $-2.4( \pm 0.72)$ \\
Age (years) & $12.1( \pm 1.0)$ & $12.1( \pm 0.95)$ \\
Bone age (years) & $11.4( \pm 1.1)$ & $11.1( \pm 0.9)$ \\
Height SDS & $-2.7( \pm 0.68)$ & $-2.8( \pm 0.70)$ \\
Target height SDS & $-0.65( \pm 0.77)$ & $-0.46( \pm 0.75)$ \\
Tanner stage 2 & 18 & 15 \\
Tanner stage 3 & 4 & 4 \\
\hline
\end{tabular}




\section{Body composition}

At the start of GnRHa treatment, mean fat mass SDS $_{\text {height }}$ was significantly lower than the population mean in both groups $(P<0.0001$; Fig. 2$)$. After 1 year of combined treatment, fat mass SDS $_{\text {height }}$ had decreased significantly in group B only $(P<0.0001)$. At 3 months after the stop of GnRHa treatment, fat mass SDS height had significantly increased in both groups $(P=0.0001)$. In group $\mathrm{A}$, fat mass $\mathrm{SDS}_{\text {height }}$ was significantly higher compared with baseline $(P<0.0001)$, and was similar to the population mean. In group $\mathrm{B}$, fat mass $\mathrm{SDS}_{\text {height }}$ returned to values comparable to those at baseline, remaining significantly lower than the population mean $(P=0.03)$.

After 1 year of combined treatment, percentage trunk fat had increased significantly in group A only $(P=0.002)$. At 3 months after the stop of GnRHa treatment, percentage trunk fat had significantly increased in both groups, but to a lower extent in group B. Percentage trunk fat was significantly higher compared with baseline in both groups $(P<0.001)$.

At the start of GnRHa treatment, lean body mass SDS $_{\text {height }}$ was significantly lower than the population mean in both groups $(P<0.0001$; Fig. 2$)$. At 3 months
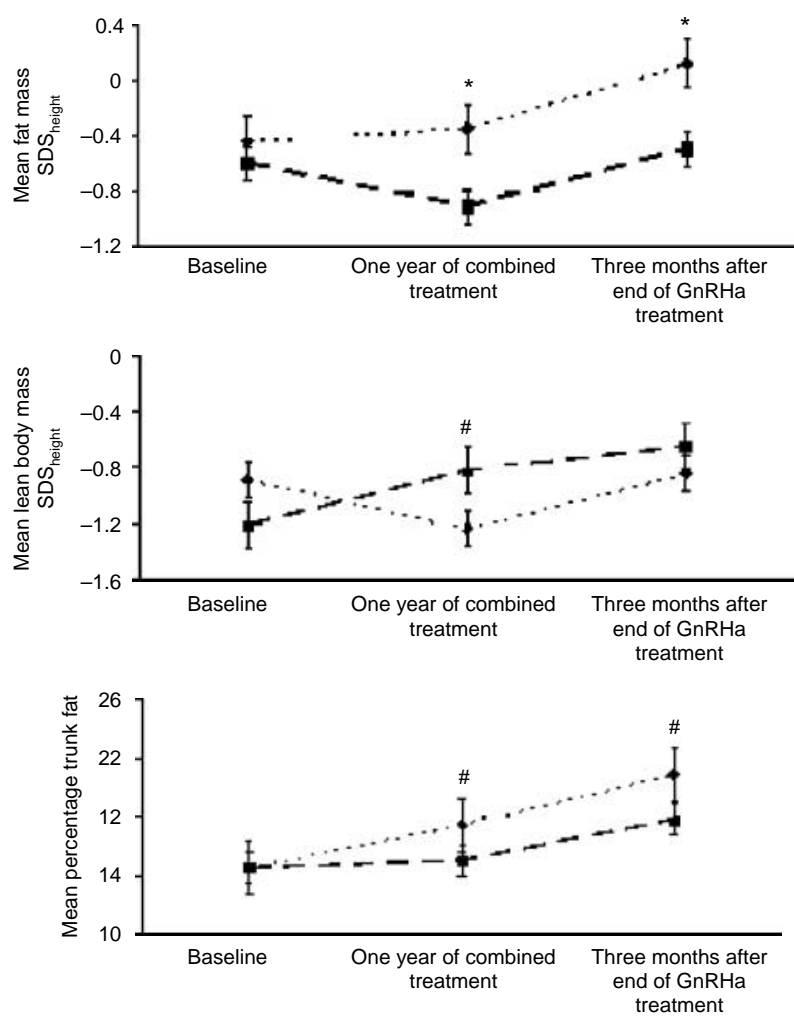

Figure 2 Changes in body composition and percentage trunk and limb fat during the study period. Data are expressed as mean ( \pm S.E.M). Diamonds represent values during treatment with $\mathrm{GnRHa}$ and $1 \mathrm{mg} \mathrm{GH} / \mathrm{m}^{2}$ per day. Squares represent values during treatment with $\mathrm{GnRHa}$ and $2 \mathrm{mg} \mathrm{GH} / \mathrm{m}^{2}$ per day. Mean percentage trunk fat $=$ (trunk fat/total trunk mass) $\times 100 .{ }^{*} P<0.01,{ }^{\#} P<0.05$. after the end of GnRHa treatment, lean body mass SDS $_{\text {height }}$ had significantly increased in group B only $(P=0.007)$. In both groups, lean body mass SDS $_{\text {height }}$ remained significantly lower compared with the population mean.

During the study period, there was a significant $\mathrm{GH}$ dose effect on fat mass $\operatorname{SDS}_{\text {height }}(P=0.01)$ and percentage trunk fat $(P=0.03)$. The $\mathrm{GH}$ dose effect on lean body mass SDS $_{\text {height }}$ showed a trend towards significance $(P=0.07)$.

\section{Blood pressure}

At the start of GnRHa treatment, mean systolic BP was significantly higher than the population mean $(P<0.0001$; Table 2). A mean systolic BP SDS above the normal range $(>+2$ SDS) was found in $27 \%$ of the study subjects.

Systolic BP SDS did not significantly change during the study period, and was similar in groups A and B. Diastolic BP SDS had significantly increased after 1 year of combined treatment and remained higher at 3 months after the stop of GnRHa treatment, albeit still within the normal range. All values were comparable between groups $\mathrm{A}$ and $\mathrm{B}$.

\section{Insulin sensitivity and $\beta$-cell function}

Si had significantly decreased and AIR had significantly increased after 1 year of combined treatment. Sg and DI remained comparable to baseline (Table 2). After 1 year of combined treatment, fasting insulin levels and HOMA-IR had significantly increased as well.

At 3 months after the end of GnRHa treatment, insulin levels and HOMA-IR remained similar to the levels after 1 year of combined treatment. All values were comparable between groups $\mathrm{A}$ and $\mathrm{B}$.

\section{Lipid profile}

Mean serum lipid levels remained within the normal range during the study period, and were similar in groups A and B. At the start of GnRHa treatment, $\operatorname{lp}(\mathrm{a})$ levels were above the normal range $(>0.3 \mathrm{~g} / \mathrm{l})$ in $27 \%$ of the children. During the study period, percentages were 34 and $24 \%$ after 1 year of combined treatment and at 3 months after the stop of GnRHa treatment respectively.

\section{Overnight GH profiles during combined treatment}

At the start of GH treatment (3 months after the start of GnRHa treatment), mean and maximum GH levels were comparable for groups A and B and for boys and girls.

After 1 year of combined treatment, mean and maximum GH levels significantly increased in both 
Table 2 Blood pressure, insulin sensitivity, and lipids at the start of GnRHa treatment, after 1 year of combined treatment and 3 months after the end of $\mathrm{GnRHa}$ treatment in short small for gestational age (SGA) children. Data are expressed as model estimate (95\% Cl), after adjustment for gender and Tanner stage at baseline.

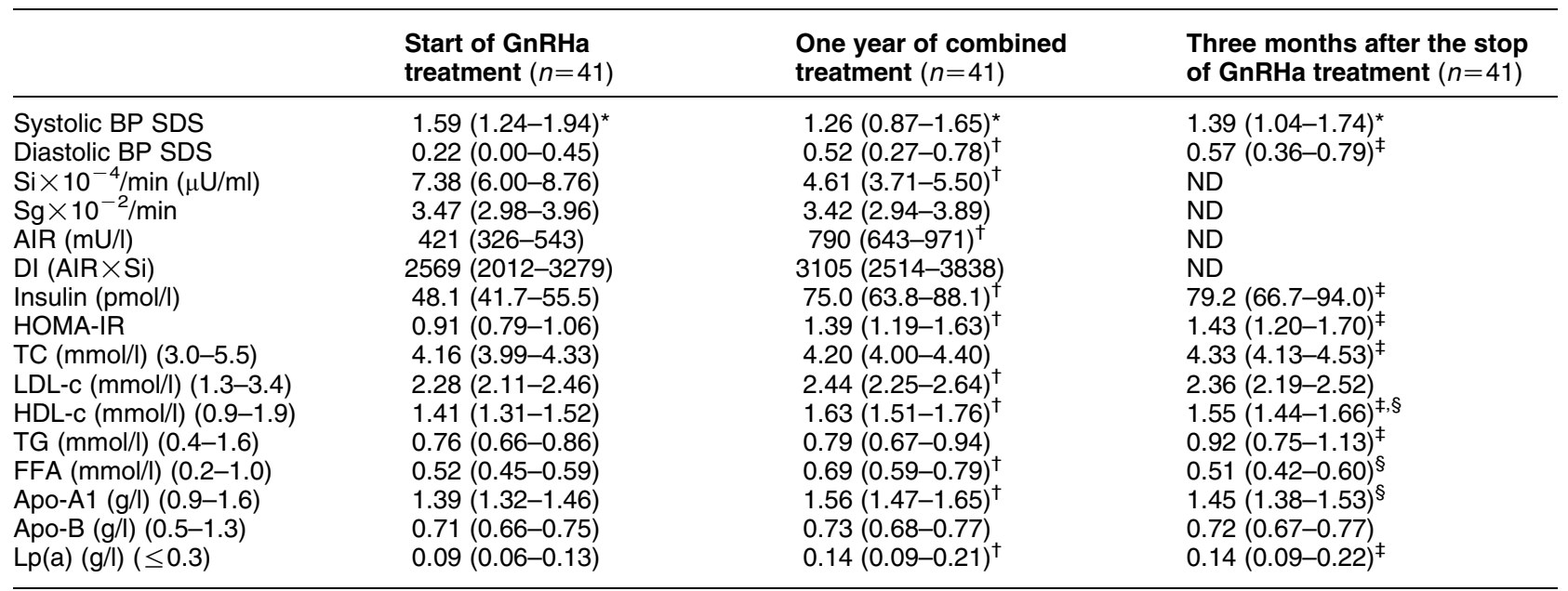

AIR, DI, insulin levels, HOMA-IR, and triglyceride and Ip (a) levels were log-transformed prior to analysis. The values between brackets represent reference ranges for healthy children; ND, not determined. ${ }^{\star} P<0.0001$ compared with the population mean $\left(0\right.$ SDS); ${ }^{\dagger} P<0.03$ : 1 year of combined treatment, compared with the start of GnRHa treatment; ${ }^{\ddagger} P<0.03$ : 3 months after the stop of GnRHa treatment, compared with the start of GnRHa treatment; ${ }^{\S} P<0.02$ : 3 months after the stop of $\mathrm{GnRHa}$ treatment, compared with 1 year of combined treatment.

groups, and levels were significantly higher in group B (Table 3). Following the s.c. GH injection at $2000 \mathrm{~h}, \mathrm{GH}$ levels remained significantly higher above 40 and $20 \mathrm{mU} / \mathrm{l}$ in group B compared with group A $(P<0.0001$; Fig. 3). No correlations were found between $\mathrm{GH}$ profile characteristics and age, bone age, gender, pubertal stage, and peak LH level during a GnRH agonist test and fat mass SDS.

\section{IGF1 and IGFBP3 levels during combined treatment}

At the start of GH treatment (3 months after the start of GnRHa treatment), IGF1 and IGFBP3 levels were significantly lower than the respective population means $(P<0.0001$; Table 3$)$. IGF1 levels were comparable for groups $\mathrm{A}$ and $\mathrm{B}$ and for boys and girls. IGFBP3 levels were significantly lower in group A, but were comparable for boys and girls. IGF1 levels correlated with IGFBP3 levels $(r=0.62, P<0.0001)$ and mean GH levels $(r=0.36, P=0.04)$. IGFBP3 levels correlated with mean GH levels $(r=0.39, P=0.03)$.

After 1 year of combined treatment, IGF1 levels increased to levels significantly higher than the population mean $(P<0.0001)$ in both groups. IGF1 levels were significantly higher in group B. In group B, $88.9 \%$ of the children had IGF1 levels in the highest quintile ( $>0.84$ SDS) and $27.8 \%$ had IGF1 levels above 2 SDS compared with $43.8 \%(P=0.005)$ and $6.3 \%(\mathrm{NS})$ of children in group A respectively. IGF1 levels were comparable for boys and girls.

IGFBP 3 levels increased significantly and similarly in both groups. Compared with the population mean,
IGFBP3 levels remained only significantly lower in group A $(P=0.01)$. Levels were comparable for boys and girls.

During combined treatment, IGF1 levels only correlated with IGFBP3 levels $(r=0.50, P=0.003)$.

\section{Discussion}

Our study is the first to report metabolic effects in pubertal short SGA children during combined treatment with a GnRHa and 1 or $2 \mathrm{mg} \mathrm{GH} / \mathrm{m}^{2}$ per day. Children treated with GnRHa and the higher GH dose of $2 \mathrm{mg} / \mathrm{m}^{2}$ per day developed less fat mass SDS height $_{\text {, less }}$ percentage trunk fat, and more lean body mass $\mathrm{SDS}_{\text {height }}$. BP, Si, and lipid profile were similar in both $\mathrm{GH}$ dosage groups. As expected, Si significantly decreased, but the DI did not change in either group. Lipids remained within normal reference ranges. GH and IGF1 levels were significantly higher in children treated with GnRHa and $2 \mathrm{mg} \mathrm{GH} / \mathrm{m}^{2}$ per day.

At the start of GnRHa treatment, fat mass SDS $_{\text {height }}$ was significantly lower than the population mean in both groups, consistent with findings in prepubertal short SGA children (11). In children treated with GnRHa and $2 \mathrm{mg} \mathrm{GH} / \mathrm{m}^{2}$ per day, fat mass SDS $_{\text {height }}$ remained significantly lower than the population mean. Percentage trunk fat increased in both $\mathrm{GH}$ dosage groups, but to lower values in children treated with GnRHa and $2 \mathrm{mg} \mathrm{GH} / \mathrm{m}^{2}$ per day. Several studies reported an increase in fat mass or BMI SDS during GnRHa treatment in children with CPP $(1,2)$. This might be explained by lower GH levels during GnRHa treatment, as reported in children with GH deficiency 


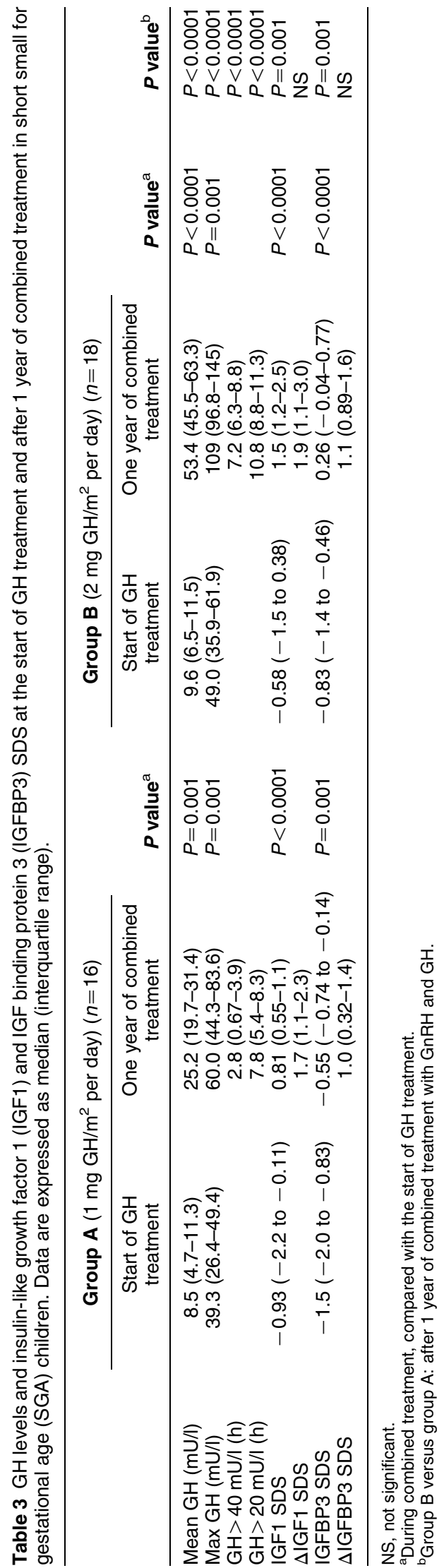

(27). In contrast to GnRHa, GH has well-documented lipolytic effects (28). GH treatment in prepubertal short SGA children resulted in a significant decrease in fat mass SDS $_{\text {height }}$, especially in the first treatment year (11). The significant differences between the two GH dosage groups in our study can be explained by the fact that treatment with $2 \mathrm{mg} \mathrm{GH} / \mathrm{m}^{2}$ per day counteracts the effect of simultaneous treatment with a GnRHa, whereas treatment with $1 \mathrm{mg} \mathrm{GH} / \mathrm{m}^{2}$ per day is insufficient to prevent children from gaining fat mass during GnRHa treatment. Epidemiological studies have shown that low birth weight followed by catch-up in fat mass during childhood and adolescence, even when fat mass remained within the normal range, was associated with a higher risk of developing type 2 diabetes and cardiovascular disease (29-31). Follow-up until adult height is required to investigate the long-term effects of changes in body composition and metabolic profile in short SGA children treated with GnRHa and GH.

At the start of GnRHa treatment, lean body mass SDS $_{\text {height }}$ was significantly lower than the population mean in both $\mathrm{GH}$ dosage groups. It was previously shown that older prepubertal short SGA children have a lower lean body mass SDS height $_{\text {compared with younger }}$ ones (11). During the study period, lean body mass SDS $_{\text {height }}$ increased significantly in children treated with GnRHa and $2 \mathrm{mg} \mathrm{GH} / \mathrm{m}^{2}$ per day only. In contrast, in children with CPP, lean body mass SDS adjusted for gender and age decreased significantly during GnRHa treatment (2). We therefore conclude that treatment with $2 \mathrm{mg} \mathrm{GH} / \mathrm{m}^{2}$ per day, in combination with a GnRHa, results in an increase in lean body mass SDS $_{\text {height }}$ in older short SGA children.

At the start of GnRHa treatment, mean systolic BP SDS was significantly higher than the population mean. Higher BP in childhood has been associated with an increased risk of developing hypertension in adulthood (32). Systolic BP SDS did not change significantly during the study period. This is compatible with previous findings, where a significant decrease in BP SDS was found only after 3 years of GH treatment $(10,33)$.

At the start of GnRHa treatment, Si was lower and insulin secretion was higher in our pubertal short SGA children compared with the reported values in prepubertal short SGA children (22). This was expected, since healthy pubertal children have a physiologic IR with a compensatory increase in insulin secretion (34). During 1 year of combined treatment, Si significantly decreased and AIR significantly increased. The DI remained similar to baseline, reflecting that $\beta$-cells were able to compensate for the reduction in $\mathrm{Si}$ by increasing their insulin secretion. Si and AIR were comparable between both GH dosage groups. Since IGF 1 levels were significantly higher during treatment with GnRHa and $2 \mathrm{mg} \mathrm{GH} / \mathrm{m}^{2}$ per day, albeit within the normal range, this might be explained by the fact that the insulin-like effects of IGF1 counterbalance the insulin-antagonistic effects of GH (35). 


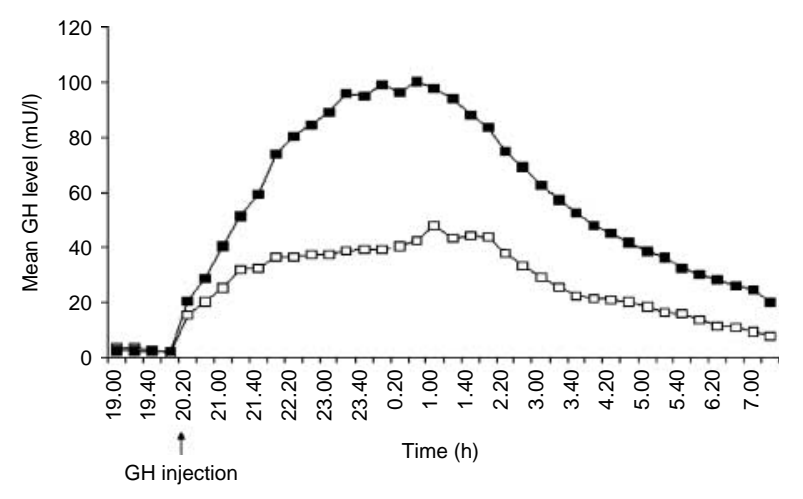

Figure 3 Mean GH levels for each time point during the overnight $\mathrm{GH}$ profile after 1 year of combined treatment with $\mathrm{GnRHa}$ and $\mathrm{GH}$. Open squares represent group $\mathrm{A}$ and solid squares represent group B.

At the start of GnRHa treatment, mean serum lipid levels were within the normal range, although $\operatorname{lp}(\mathrm{a})$ levels were above the normal range $(>0.3 \mathrm{~g} / \mathrm{l})$ in $27 \%$ of the pubertal short SGA children. High $\operatorname{lp}(\mathrm{a})$ levels have been associated with an increased risk of developing cardiovascular disease in several studies $(36,37)$. Although some lipids showed a significant temporary increase (LDL-c, FFA, and Apo-A1 levels), and others increased more steadily over time (TC and TG levels), the actual increase and subsequent decrease in levels were very small, and lipids were similar in both groups. The clinical significance of these small changes in lipid levels is therefore considered negligible.

During combined treatment, mean and maximum GH levels were lower in our study group compared with levels in prepubertal SGA children treated with GH only (38). Moreover, maximum GH levels in children treated with GnRHa and $2 \mathrm{mg} \mathrm{GH} / \mathrm{m}^{2}$ per day were similar to maximum $\mathrm{GH}$ levels in prepubertal children treated with $1 \mathrm{mg} \mathrm{GH} / \mathrm{m}^{2}$ per day. In the latter study, GH levels were determined with the same assay in the same laboratory. We previously reported that GH levels significantly decreased during 3 months of GnRHa treatment (16), similar to reports in patients with precocious puberty treated with GnRHa (39-41). This is probably partly due to diminution of sex steroids (42). Thus, the lower GH levels in our study group might well be a result of simultaneous treatment with GH and a GnRHa. Nonetheless, following a s.c. GH injection at $2000 \mathrm{~h}, \mathrm{GH}$ levels in short SGA children treated with GnRHa and $2 \mathrm{mg} \mathrm{GH} / \mathrm{m}^{2}$ per day remained above $20 \mathrm{mU} / \mathrm{l}$ for almost $11 \mathrm{~h}$, demonstrating that these children have elevated GH levels for a great part of the day. GH and IGF1 levels increased significantly in both GH dosage groups, but to significantly higher levels in the $2 \mathrm{mg} \mathrm{GH} / \mathrm{m}^{2}$ per day group. Dose-dependent rises have been described in prepubertal short children born SGA, GH-deficient adolescents, and girls with Turner syndrome $(38,43,44)$. The percentage of children with IGF1 SDS above 2 SDS was not significantly different between the groups. However, $27.8 \%$ of the children treated with $2 \mathrm{mg} \mathrm{GH} / \mathrm{m}^{2}$ per day had IGF1 levels above 2 SDS. Concern has been expressed about the association of high IGF1 levels during several years and long-term cancer risk (45). Although pubertal short SGA children will be treated for a relatively short period of time, it is important to monitor IGF1 levels during the treatment.

Our study has some limitations. Since GH treatment in short SGA children was approved by the FDA in 2001 and by the EMEA in 2003, our medical ethics committee did not allow us to treat pubertal short SGA children solely with a GnRHa or to include a control group without any treatment. We did not include a study group of pubertal short SGA children treated with GH only, because this is investigated in another GH trial. In the future, it would be interesting to compare adult height results between these two studies. Since many clinicians started treating short SGA children with GnRHa and GH, despite the fact that there are no safety data, it is important to report safety data on metabolic profile in relation to GH and IGF1 levels before adult height data will be available. Adult height data will have to be awaited before a definitive conclusion can be drawn whether combined treatment with GnRHa and either 1 or $2 \mathrm{mg} \mathrm{GH} / \mathrm{m}^{2}$ per day will result in an optimal adult height without adversely affecting metabolic outcome.

In conclusion, our study is the first to report that 2 years of combined treatment with a GnRHa and either 1 or $2 \mathrm{mg} \mathrm{GH} / \mathrm{m}^{2}$ per day does not adversely affect body composition and metabolic profile of short SGA children who come under medical attention at the onset of puberty. There was a dose-dependent effect on fat mass SDS $_{\text {height, }}$, percentage trunk fat, lean body mass SDS $_{\text {height }}$, and GH and IGF1 levels in favor of treatment with GnRHa and the higher GH dose of $2 \mathrm{mg} / \mathrm{m}^{2}$ per day. $\mathrm{BP}, \mathrm{Si}$, and lipid profile were similar between the two GH dosage groups.

\section{Declaration of interest}

The authors declare that there is no conflict of interest that could be perceived as prejudicing the impartiality of the research reported.

\section{Funding}

This investigator-initiated study received a financial contribution from Pfizer Farma B.V., The Netherlands.

\section{Acknowledgements}

We thank all children and their parents for participating in this study. We very much appreciate the technical assistance of Mrs Jolanda van Houten, research nurse. Participating physicians were R J H Odink and J J J Waelkens, Catharina Hospital, Eindhoven, The Netherlands; Dr W M Bakker-van Waarde, University Medical Center Groningen, Groningen, The Netherlands; Dr C Noordam, Radboud University Medical Center Nijmegen, Nijmegen, The Netherlands; Dr C Westerlaken, Canisius Wilhelmina Hospital, Nijmegen, The Netherlands; 
and Dr E J Sulkers, Walcheren Hospital, Vlissingen, The Netherlands. We would like to thank Dr W H Hackeng for his GH assays and for analyzing the FSIGTs. Mrs J Sluimer and Prof. E P Krenning, head of the department of nuclear medicine, are greatly acknowledged for the DXA facilities and equipment. Dr I M van der Sluis is greatly acknowledged for her help in analyzing the height-adjusted Z-scores for the DXA parameters. We are grateful for the support of the nurses working on the Children's Ward, Sophia Children's Hospital. We appreciate the financial support of the Vereniging Trustfonds Erasmus Universiteit Rotterdam for conference visits.

\section{References}

1 Pasquino AM, Pucarelli I, Roggini M \& Segni M. Adult height in short normal girls treated with gonadotropin-releasing hormone analogs and growth hormone. Journal of Clinical Endocrinology and Metabolism 200085 619-622.

2 van der Sluis IM, Boot AM, Krenning EP, Drop SL \& de Muinck Keizer-Schrama SM. Longitudinal follow-up of bone density and body composition in children with precocious or early puberty before, during and after cessation of GnRH agonist therapy. Journal of Clinical Endocrinology and Metabolism 200287 506-512.

3 Palmert MR, Mansfield MJ, Crowley WF Jr, Crigler JF Jr, Crawford JD \& Boepple PA. Is obesity an outcome of gonadotropin-releasing hormone agonist administration? Analysis of growth and body composition in 110 patients with central precocious puberty. Journal of Clinical Endocrinology and Metabolism $1999844480-4488$.

4 Arrigo T, De Luca F, Antoniazzi F, Galluzzi F, Segni M, Rosano M, Messina MF \& Lombardo F. Reduction of baseline body mass index under gonadotropin-suppressive therapy in girls with idiopathic precocious puberty. European Journal of Endocrinology 2004150 533-537.

5 Ranke MB \& Lindberg A. Growth hormone treatment of short children born small for gestational age or with Silver-Russell syndrome: results from KIGS (Kabi International Growth Study), including the first report on final height. Acta Paediatrica. Supplementum $1996 \mathbf{4 1 7} 18-26$.

6 Van Pareren Y, Mulder P, Houdijk M, Jansen M, Reeser M \& Hokken-Koelega A. Adult height after long-term, continuous growth hormone $(\mathrm{GH})$ treatment in short children born small for gestational age: results of a randomized, double-blind, doseresponse GH trial. Journal of Clinical Endocrinology and Metabolism $2003 \mathbf{8 8} 3584-3590$.

7 Ong K, Beardsall K \& de Zegher F. Growth hormone therapy in short children born small for gestational age. Early Human Development 200581 973-980.

8 Sas T, de Waal W, Mulder P, Houdijk M, Jansen M, Reeser M \& Hokken-Koelega A. Growth hormone treatment in children with short stature born small for gestational age: 5-year results of a randomized, double-blind, dose-response trial. Journal of Clinical Endocrinology and Metabolism 199984 3064-3070.

9 de Zegher F, Ong K, van Helvoirt M, Mohn A, Woods K \& Dunger D. High-dose growth hormone $(\mathrm{GH})$ treatment in non-GH-deficient children born small for gestational age induces growth responses related to pretreatment $\mathrm{GH}$ secretion and associated with a reversible decrease in insulin sensitivity. Journal of Clinical Endocrinology and Metabolism 200287 148-151.

10 Sas T, Mulder P \& Hokken-Koelega A. Body composition, blood pressure, and lipid metabolism before and during long-term growth hormone $(\mathrm{GH})$ treatment in children with short stature born small for gestational age either with or without $\mathrm{GH}$ deficiency. Journal of Clinical Endocrinology and Metabolism 2000 85 3786-3792.

11 Willemsen RH, Arends NJ, Bakker-van Waarde WM, Jansen M, van Mil EG, Mulder J, Odink RJ, Reeser M, Rongen-Westerlaken C, Stokvis-Brantsma WH, Waelkens JJ \& Hokken-Koelega AC. Longterm effects of growth hormone $(\mathrm{GH})$ treatment on body composition and bone mineral density in short children born small-for-gestational-age: six-year follow-up of a randomized controlled GH trial. Clinical Endocrinology 200767 485-492.

12 Usher R \& McLean F. Intrauterine growth of live-born Caucasian infants at sea level: standards obtained from measurements in 7 dimensions of infants born between 25 and 44 weeks of gestation. Journal of Pediatrics $1969 \mathbf{7 4}$ 901-910.

13 Fredriks AM, van Buuren S, Burgmeijer RJ, Meulmeester JF, Beuker RJ, Brugman E, Roede MJ, Verloove-Vanhorick SP \& Wit JM. Continuing positive secular growth change in The Netherlands 1955-1997. Pediatric Research 200047 316-323.

14 Tanner JM \& Whitehouse RH. Clinical longitudinal standards for height, weight, height velocity, weight velocity, and stages of puberty. Archives of Disease in Childhood $1976 \mathbf{5 1} 170-179$.

15 Cavallo A \& Zhou XH. LHRH test in the assessment of puberty in normal children. Hormone Research 199441 10-15.

16 van der Kaay DC, Rose SR, van Dijk M, Noordam C, van Rheenen E \& Hokken-Koelega AC. Reduced levels of GH during GnRH analogue treatment in pubertal short girls born small for gestational age (SGA). Clinical Endocrinology 2009 70 914-919.

17 Rosner B, Prineas RJ, Loggie JM \& Daniels SR. Blood pressure nomograms for children and adolescents, by height, sex, and age, in the United States. Journal of Pediatrics 1993123 871-886.

18 Boot AM, Bouquet J, de Ridder MA, Krenning EP \& de Muinck Keizer-Schrama SM. Determinants of body composition measured by dual-energy X-ray absorptiometry in Dutch children and adolescents. American Journal of Clinical Nutrition $1997 \mathbf{6 6}$ 232-238.

19 Cutfield WS, Bergman RN, Menon RK \& Sperling MA. The modified minimal model: application to measurement of insulin sensitivity in children. Journal of Clinical Endocrinology and Metabolism 199070 1644-1650.

20 Boston RC, Stefanovski D, Moate PJ, Sumner AE, Watanabe RM \& Bergman RN. MINMOD millennium: a computer program to calculate glucose effectiveness and insulin sensitivity from the frequently sampled intravenous glucose tolerance test. Diabetes Technology and Therapeutics 20035 1003-1015.

21 Levy JC, Matthews DR \& Hermans MP. Correct homeostasis model assessment (HOMA) evaluation uses the computer program. Diabetes Care 199821 2191-2192.

22 Arends NJ, Boonstra VH, Duivenvoorden HJ, Hofman PL, Cutfield WS \& Hokken-Koelega AC. Reduced insulin sensitivity and the presence of cardiovascular risk factors in short prepubertal children born small for gestational age (SGA). Clinical Endocrinology 200562 44-50.

23 Merriam GR \& Wachter KW. Algorithms for the study of episodic hormone secretion. American Journal of Physiology $1982 \mathbf{2 4 3}$ E310-E318.

24 Hokken-Koelega AC, Hackeng WH, Stijnen T, Wit JM, de Muinck Keizer-Schrama SM \& Drop SL. Twenty-four-hour plasma growth hormone $(\mathrm{GH})$ profiles, urinary GH excretion, and plasma insulinlike growth factor-I and -II levels in prepubertal children with chronic renal insufficiency and severe growth retardation. Journal of Clinical Endocrinology and Metabolism $1990 \mathbf{7 1}$ 688-695.

25 van der Kaay DC, de Jong FH, Laven JS \& Hokken-Koelega AC. Overnight luteinizing and follicle stimulating hormone profiles during GnRHa treatment in short girls born small for gestational age. Journal of Pediatric Endocrinology and Metabolism 200922 161-169.

26 van der Kaay DC, de Jong FH, Rose SR, Odink RJ, Bakker-van Waarde WM, Sulkers EJ \& Hokken-Koelega AC. Overnight levels of luteinizing hormone, follicle-stimulating hormone and growth hormone before and during gonadotropin-releasing hormone analogue treatment in short boys born small for gestational age. Hormone Research 200971 260-267.

27 Boot AM, Engels MA, Boerma GJ, Krenning EP \& de Muinck Keizer-Schrama SM. Changes in bone mineral density, body composition, and lipid metabolism during growth hormone $(\mathrm{GH})$ treatment in children with GH deficiency. Journal of Clinical Endocrinology and Metabolism 199782 2423-2428. 
28 Mukherjee A, Murray RD \& Shalet SM. Impact of growth hormone status on body composition and the skeleton. Hormone Research 200462 35-41.

29 Bhargava SK, Sachdev HS, Fall CH, Osmond C, Lakshmy R, Barker DJ, Biswas SK, Ramji S, Prabhakaran D \& Reddy KS. Relation of serial changes in childhood body-mass index to impaired glucose tolerance in young adulthood. New England Journal of Medicine $20043 \mathbf{5 0} 865-875$.

30 Eriksson JG, Osmond C, Kajantie E, Forsen TJ \& Barker DJ. Patterns of growth among children who later develop type 2 diabetes or its risk factors. Diabetologia $2006492853-2858$.

31 Leunissen RW, Kerkhof GF, Stijnen T \& Hokken-Koelega A. Timing and tempo of first-year rapid growth in relation to cardiovascular and metabolic risk profile in early adulthood. Journal of the American Medical Association $20093012234-2242$.

32 Bao W, Threefoot SA, Srinivasan SR \& Berenson GS. Essential hypertension predicted by tracking of elevated blood pressure from childhood to adulthood: the Bogalusa Heart Study. American Journal of Hypertension $19958657-665$.

33 Willemsen RH, van Dijk M, de Kort SW, van Toorenenbergen AW \& Hokken-Koelega AC. Plasma matrixmetalloproteinase-9 levels and blood pressure in short children born small-for-gestationalage and effects of growth hormone treatment. Clinical Endocrinology $200869264-268$.

34 Moran A, Jacobs DR Jr, Steinberger J, Hong CP, Prineas R, Luepker $\mathrm{R} \&$ \& Sinaiko AR. Insulin resistance during puberty: results from clamp studies in 357 children. Diabetes $1999 \mathbf{4 8}$ 2039-2044.

35 Yuen KC \& Dunger DB. Impact of treatment with recombinant human GH and IGF-I on visceral adipose tissue and glucose homeostasis in adults. Growth Hormone and IGF Research 2006 16 S55-S61.

36 Danesh J, Collins R \& Peto R. Lipoprotein(a) and coronary heart disease. Meta-analysis of prospective studies. Circulation 2000102 1082-1085.

37 Wilson PW. Assessing coronary heart disease risk with traditional and novel risk factors. Clinical Cardiology 200427 III7-III11.

38 van Dijk M, Mulder P, Houdijk M, Mulder J, Noordam K, Odink RJ, Rongen-Westerlaken C, Voorhoeve P, Waelkens J, StokvisBrantsma J \& Hokken-Koelega A. High serum levels of growth hormone $(\mathrm{GH})$ and insulin-like growth factor-I (IGF-I) during high-dose $\mathrm{GH}$ treatment in short children born small for gestational age. Journal of Clinical Endocrinology and Metabolism 200691 1390-1396.

39 Stanhope R, Pringle PJ \& Brook CG. Growth, growth hormone and sex steroid secretion in girls with central precocious puberty treated with a GnRH analogue. Acta Paediatrica Scandinavica 1988 77 525-530.

40 DiMartino-Nardi J, Wu R, Fishman K \& Saenger P. The effect of long-acting analog of luteinizing hormone-releasing hormone on growth hormone secretory dynamics in children with precocious puberty. Journal of Clinical Endocrinology and Metabolism 199173 902-906.

41 Saggese G, Federico G, Barsanti S \& Fiore L. The effect of administering gonadotropin-releasing hormone agonist with recombinant-human growth hormone $(\mathrm{GH})$ on the final height of girls with isolated GH deficiency: results from a controlled study. Journal of Clinical Endocrinology and Metabolism $2001 \mathbf{8 6}$ 1900-1904.

42 Delemarre-van de Waal HA, van Coeverden SC \& Rotteveel J. Hormonal determinants of pubertal growth. Journal of Pediatric Endocrinology and Metabolism 2001 14 1521-1526.

43 Jorgensen JO, Flyvbjerg A, Lauritzen T, Alberti KG, Orskov H \& Christiansen JS. Dose-response studies with biosynthetic human growth hormone $(\mathrm{GH})$ in $\mathrm{GH}$-deficient patients. Journal of Clinical Endocrinology and Metabolism 198867 36-40.

44 van Teunenbroek A, de Muinck Keizer-Schrama SM, Stijnen T, Mouton JW, Blum WF, Mercado M, Baumann G \& Drop SL. Effect of growth hormone administration frequency on 24-h growth hormone profiles and levels of other growth related parameters in girls with Turner's syndrome. Dutch Working Group on Growth Hormone. Clinical Endocrinology 199339 77-84.

45 Renehan AG, Zwahlen M, Minder C, O’Dwyer ST, Shalet SM \& Egger M. Insulin-like growth factor (IGF)-I, IGF binding protein-3, and cancer risk: systematic review and metaregression analysis. Lancet 2004363 1346-1353.

Received 16 February 2010

Accepted 21 February 2010 